\title{
Caries Prevalence, Oral Hygiene, and Oral Health Habits of Kuwaiti Infants and Toddlers
}

\author{
Huda Nazar ${ }^{a}$ Sabiha Al-Mutawa ${ }^{a}$ b Jitendra Arigac Pramod Soparkar ${ }^{\text {c }}$ \\ Ana Karina Mascarenhas ${ }^{\mathrm{e}}$ \\ a National School Oral Health Program and ${ }^{\mathrm{b}}$ Dental Department, Ministry of Health, and ${ }^{\mathrm{C}}$ National School Oral \\ Health Program, Kuwait-Forsyth, Kuwait, Kuwait; ${ }^{d}$ Forsyth Institute, Cambridge, Mass., and e College of Dental \\ Medicine, Nova Southeastern University, Fort Lauderdale, Fla., USA
}

\section{Key Words}

Dental caries · Oral hygiene · Tooth brushing · Night feeding · Bottle-feeding · Cavitated lesions · Noncavitated lesions

\section{Abstract \\ Objective: The purpose of this study was to describe the oral health, oral hygiene, and oral health habits of Kuwaiti infants and toddlers. Subjects and Methods: This cross-sectional study of a convenience sample included 336 infants and tod- dlers (156 females and 180 males). The teeth of the infants and toddlers were examined using a mirror and a light source. Oral hygiene was recorded, and then all teeth were cleaned with gauze and examined for caries. Parents were interviewed regarding their children's feeding habits, brush- ing or tooth cleaning, and night feeding. The evaluation cri- teria for caries were sound teeth, noncavitated lesions, cavi- tated lesions, filled teeth, and missing teeth. Results: The mean age was $11.1 \pm 2.4$ months (range 2-23). Of the 336 subjects, 247 (73\%) had good oral hygiene, 64 (19\%) had par- ents who brushed or cleaned their infants' and toddlers' teeth; 288 (86\%) were bottle-fed, and 290 (86\%) were also night fed. The mean number of teeth upon examination was $4.6 \pm 2.7$ (range 2-8). Three percent of the infants and tod-}

dlers had caries. Cavitated lesions were present in 6 patients (1.8\%), while $4(1.2 \%)$ had noncavitated lesions. The mean d1d2t (caries teeth: noncavitated lesions and cavitated lesions) was $0.03 \pm 0.3$, and the mean $\mathrm{d} 1 \mathrm{~d} 2 \mathrm{~s}$ (carious surfaces) was $0.07 \pm 0.5$. Conclusion: The caries prevalence and severity was low in infants and toddlers. However, poor oral health practices and habits as well as unhealthy feeding practices that could affect the future caries prevalence were noted.

(c) 2013 S. Karger AG, Basel

\section{Introduction}

Early childhood caries is a chronic preventable disease of childhood. Early childhood caries is also a transmissible infectious disease that is caused by Streptococcus mutans, and the main source of the bacterium in the infant's oral flora is the mother or the primary caregiver [1]. The American Academy of Pediatric Dentistry defines early childhood caries as 'the presence of one or more decayed (noncavitated, or cavitated lesions), missing (due to caries), or filled teeth surfaces in any primary tooth in a child 71 months of age or younger' [2]. Early childhood caries can affect the infant's primary teeth soon after eruption (6-12 months) or it can affect the teeth of preschool children [3]. Early childhood 
caries increases a child's risk of future dental caries in posterior primary teeth [4] or in permanent teeth [5]. The immediate consequence of untreated caries is pain [6] and a common treatment is extraction, which could result in future orthodontic problems and is costly [7].

Data on the oral health of infants and toddlers are scarce, with few local studies available in the literature in the USA. A Head Start program in Arizona (USA) found that, at 11-12 months of age, caries was mainly seen in maxillary anterior teeth. At the age of 13-15 months, caries was seen at the fissures of posterior teeth or in both fissures of posterior teeth and maxillary anterior teeth [3]. When ethnic populations were studied, data showed that American Indian and Alaska Native children aged 2-4 years had 5 times the rate of dental decay compared to all children, and untreated decay in these age groups was 2-3 times higher than in the general US population [8].

Early studies done in the 1920s and 1990s show inconsistency in the occurrence of caries in Kuwaiti children 4-6 years (11.5\%) [9], 1.4-4 years (19\%) [10], and 3-7 years $(22 \%)$ [11]. These data show an increase in early childhood caries prevalence among Kuwaiti children. Unfortunately, there are no recently published studies on early childhood caries in Kuwaiti children and, because caries is an entirely preventable disease, it is important to know how early this disease begins in Kuwaiti children and the practices that might lead to this disease.

Hence, the objective of this study was to describe the oral health status and habits of Kuwaiti infants and toddlers. Also, these data would be useful to plan and implement oral health programs for the population.

\section{Subjects and Methods}

In 2006, as part of a clinical trial on the effectiveness of fluoride varnish, data on demographic, dental, and other oral health-related factors in Kuwaiti infants and toddlers were collected. This study was approved by the Ministry of Health, Kuwait, along with the School Oral Health Research Committee. This was a crosssectional study carried out under Al-Ahmadi School Oral Health Program, Al-Ahmadi governorate, Kuwait, at its dental center. The dental center is part of a building that houses all medical specialty clinics, in addition to a vaccination clinic open in the mornings and afternoons. A convenience sample of infants and toddlers attending the vaccination clinic was used. The inclusion criteria were: possession of Kuwaiti citizenship, age 6 months to 4 years, having at least 2 erupted primary teeth, and being in good health. Exclusion criteria were: infants and toddlers with medical problems, such as cardiac diseases and diabetes.

To recruit patients into this study, a trained dental assistant was posted at the vaccination clinic and approached parents, reviewed the inclusion criteria, and, if the infant was eligible for the study, referred the parents to the dental clinic. Two calibrated dentists (G.A. and H.A.) were the examiners. These two dentists were provided with the inclusion and exclusion criteria that the dental assistant had used. The dentists were also provided with a manual describing the procedure, and pictures of noncavitated lesions (white spot lesions) and cavitated lesions to be sure that they could distinguish the noncavitated lesions from sound teeth. Both examiners were standardized using intra- and interexaminer calibrations before the onset of the study.

The dentist explained to the parents the study and the procedures to be performed on their infant or toddler during the visit. The explanation included the information that an oral examination and a parental interview would be performed, verbal oral health education would be imparted to the parents, and a referral to a pediatric dentist would be made if needed. Informed consent was obtained from the parents.

Data collected at the examination from the parents included the infant's name, the date of the visit, the date of birth, gender, the identification number, tooth brushing/cleaning practices, night feeding, and the feeding method (breast or bottle).

An oral examination was performed by the dentists. The kneeto-knee position was used because the subjects were infants/toddlers. Oral hygiene was recorded. All teeth were cleaned with gauze and examined for caries using a mirror and a light source. Data were recorded on a chart designed for this study. The criteria used to diagnose caries were as follows: sound tooth: no pits or fissure discoloration, and no catch with the probe; noncavitated lesions (early lesions): pit and fissure surfaces with either opacity or brownish discoloration without any cavitation or presence of white opacity along the gingival margins of smooth surfaces; carious teeth (cavitated lesions): discolored pits and fissures with a catch on probing; filled teeth or surfaces: any tooth or surface with a restoration, and extracted teeth: any missing tooth considered extracted due to caries.

Using these criteria, the decayed, missing, and filled tooth (dmft) and surface ( $\mathrm{dmfs}$ ) indexes were calculated by summing the early lesions and the carious, filled, and extracted teeth. However, as there were no subjects with filled and extracted teeth, the $\mathrm{dmft}$ and $\mathrm{dmfs}$ represent the decayed teeth $(\mathrm{dt})$ and surfaces $(\mathrm{ds})$. Additionally, two levels of caries severity were calculated. The first caries severity variable included the noncavitated lesions and the cavitated lesions ( $\mathrm{d} 1 \mathrm{~d} 2 \mathrm{t}$ and $\mathrm{d} 1 \mathrm{~d} 2 \mathrm{~s})$, and the second caries severity variable included the cavitated lesions only ( $\mathrm{d} 2 \mathrm{t}$ and $\mathrm{d} 2 \mathrm{~s}$ ).

Good oral hygiene was defined as teeth without any dental plaque or food debris around them, while poor oral hygiene was defined as the presence of any dental plaque or food debris around the teeth. At the end of the examination and the parental interview, the dentist gave the parents educational brochures about breastfeeding benefits, tooth brushing, and early childhood caries and fluoride varnish.

Three hundred thirty-six infants and toddlers were included in this study (156 females and 150 males). The data collected was coded and then entered into a specifically designed data entry program using Epi Info version 3.5.1 to reduce data errors. Data were then exported to SAS version 9.1 for further analyses. Descriptive analyses using means \pm SD and proportions were performed. Bivariate and multivariate analyses to evaluate predictors of caries in this infant population were planned; however, given the low prevalence of caries seen, they were performed but are not reported here as they are not appropriate because of multiple cells with zero value. 


\section{Results}

The demographic variables and descriptive analysis of the oral hygiene and oral health habits of the subjects are given in table 1 . The mean age at examination was $11.1 \pm$ 2.4 months.

Of the 336 infants and toddlers, 247 (73.3\%) had good oral hygiene, $64(19 \%)$ had parents who brushed or cleaned their child's teeth, 288 (86\%) were bottle-fed, and 290 (86\%) were night fed. The mean number of teeth at examination was $4.6 \pm 2.7$ (range 2-8). The prevalence of caries was $1.2 \%$ for noncavitated lesions and $1.8 \%$ for cavitated caries, as shown in table 2 . At the tooth level, the mean $\mathrm{d} 1 \mathrm{~d} 2 \mathrm{t}$ was $0.03 \pm 0.3$ and the mean $\mathrm{d} 2 \mathrm{t}$ was $0.008 \pm$ 0.12 . At the surface level, the mean $\mathrm{d} 1 \mathrm{~d} 2 \mathrm{~s}$ was $0.07 \pm 0.5$ and the mean $\mathrm{d} 2 \mathrm{~s}$ was $0.02 \pm 0.29$.

\section{Discussion}

The main finding of this study was that the caries prevalence and severity in this age group was low, with only $3 \%$ having caries and a mean $\mathrm{d} 1 \mathrm{~d} 2 \mathrm{t}$ of $0.03 \pm 0.3$ and a mean $\mathrm{d} 1 \mathrm{~d} 2 \mathrm{~s}$ of $0.07 \pm 0.5$. Although the caries prevalence was low, this study also showed that, at least in some of the Kuwaiti infants and toddlers studied, the caries process started soon after tooth eruption. Given that previous studies of Kuwaiti children have shown a higher and increasing prevalence and severity of caries [9-11], Kuwaiti children should be continuously monitored to determine at what age caries manifests in them and to intervene with prevention.

Our study of Kuwaiti infants and toddlers also showed that this population had poor habits that are known to cause caries, such as bottle-feeding, night feeding, and a lack of tooth brushing or cleaning. Compared to other infant and toddler populations, twice as many children $(86 \%)$ in our study were bottle-fed at night compared to approximately $40 \%$ in the Head Start program in Arizona [3]. This is probably due to the large cultural differences between the two countries that need to be accounted for when counseling parents and planning programs. It is also interesting to note that the mean number of teeth at 12 months of age in US infants was 8.3 [3], whereas in our study it was 4.6 (about 50\% less). This shows that tooth eruption is faster among US infants compared to Kuwaiti infants. This could account for the lower early childhood caries prevalence and severity seen; this has implications for prevention as there are fewer teeth at risk in Kuwaiti infants, and it needs to be explored further.

Oral Health Status of Infants and Toddlers

Table 1. Descriptive analysis of the demographics, oral hygiene, and oral health habits of 336 Kuwaiti infants at 11 months

\begin{tabular}{lc}
\hline Males, $\mathrm{n}(\%)$ & $180(53.7)$ \\
Females, $\mathrm{n}(\%)$ & $156(46.3)$ \\
Age & \\
$\quad$ Mean \pm SD, months & $11.1 \pm 2.4$ \\
$\quad$ Range, months & $2-23$ \\
Good oral hygiene, n (\%) & $247(73.3)$ \\
Brushing, n (\%) & $64(19.0)$ \\
Bottle-feeding, n (\%) & $288(86)$ \\
Night feeding, n (\%) & $290(86)$ \\
\hline
\end{tabular}

Table 2. Descriptive analysis of caries prevalence and severity in Kuwaiti infants at 11 months

\begin{tabular}{lc}
\hline Noncavitated lesions, $\mathrm{n}(\%)$ & $4(1.2)$ \\
Caries prevalence, $\mathrm{n}(\%)$ & $6(1.8)$ \\
Mean d1d2t \pm SD (cavitated, noncavitated) & $0.03 \pm 0.3$ \\
Mean d2t \pm SD (cavitated) & $0.008 \pm 0.12$ \\
Mean d1d2s \pm SD (cavitated, noncavitated) & $0.07 \pm 0.5$ \\
Mean d2s \pm SD (cavitated) & $0.02 \pm 0.29$ \\
\hline
\end{tabular}

Comparing the prevalence and severity to other populations, in a study in Thailand by Thitasomakul et al. [12], the caries prevalence was very high at $22.8 \%$ among infants aged 12 months, and it was $68 \%$ at 18 months. Similarly, in the US Head Start study $25 \%$ of children had caries by 34-36 months of age [3]. Again, this finding could be due to the lower number of erupted teeth seen in Kuwaiti infants and toddlers.

There were several strengths in this study. It described the prevalence and severity of caries, oral hygiene, and oral health habits among Kuwaiti infants and toddlers, which have not been described before. Another potential strength is in the inclusion of only healthy infants. Vaccination visits tend to be postponed in sick infants as a result of their medical conditions, and many medications contain sugar, which is known to cause caries; this would have affected the study results and would possibly have resulted in overestimated caries outcomes.

There were several limitations in this study. The sample was taken for convenience from the vaccination clinic, and so it might not be representative of infants and toddlers in Kuwait. Additionally, initially the intent was 
also to perform bivariate and multivariate analyses to evaluate predictors of caries in the infant/toddler population; however, the prevalence of caries was so low (with only 10 infants having caries) that the model was not useful.

The low prevalence of caries notwithstanding, a preventive oral health program needs to be designed and implemented for infants and toddlers in the age group of 1-4 years. This program should be a collaborative effort among primary health care physicians, pediatricians, and dental specialists in Kuwait and should target young parents and expectant mothers.

\section{Conclusion}

Caries prevalence was low at the infant/toddler age, yet unhealthy feeding practices and poor oral hygiene which may lead to caries were detected. Hence, prevention through an oral health education program is recommended.

\section{Acknowledgement}

We acknowledge all dentists and dental assistants who helped recruit the children, record data on the examination chart, and examine the children during this study.

\section{References}

1 Berkowitz R: Causes, treatment and prevention of early childhood caries: a microbiological perspective. J Can Dent Assoc 2003;69: 304-307.

2 American Academy of Pediatric Dentistry: Early childhood caries definition. www.aapd. org/assets/2/7/ECCstats (accessed February 4, 2010).

3 Douglass J, Tinanoff N, Tang J, et al: Dental caries patterns and oral health behaviors in Arizona infants and toddlers. Community Dent Oral Epidemiol 2001;29:14-22.

-4 O'Sullivan DM, Tinanoff N: Maxillary anterior caries association with increased risk on other primary teeth. J Dent Res 1993;72: 1577-1580.
5 Li Y, Wang W: Predicting caries in permanent teeth from caries in primary teeth: an eightyear cohort study. J Dent Res 2002;81:561566.

6 Vargas C, Monajemy N, Khurana P, et al: Oral health status of preschool children attending Head Start in Maryland, 2000. Pediatr Dent 2002;24:257-263.

7 Griffin S, Gooch B, Eugenio B, et al: Dental services, costs, and factors associated with hospitalization for Medicaid-eligible children, Louisiana 1996-1997. J Public Health Dent 2000;60:21-27.

8 Office of Minority Health: Oral health. http:// raceandhealth.hhs.gov/ (accessed February $23,2010)$.
9 Soparker P: Nursing bottle syndrome in $\mathrm{Ku}$ wait. J Dent Res 1986;65:745.

10 Al Dashti A, Williams S, Crusen M: Breastfeeding, bottle-feeding and dental caries in Kuwait, a country with low-fluoride levels in water supply. Community Dent Health 1995; 12:42-47.

11 Murtomaa H, Al Zaabi F, Morris R, et al: Caries experience in a selected group of children in Kuwait. Acta Odontol Scand 1996;53:389391.

12 Thitasomakul S, Thearmontree A, Piwat S, et al: A longitudinal study of early childhood caries in 9- to 18-month-old Thai infants. Community Dent Oral Epidemiol 2006;34: 429-436. 